\title{
Systemic lupus erythematosus, eosinophilia and Löffler's endocarditis. An unusual association
}

\author{
M. Thomeer*, Ph. Moerman**, R. Westhovens ${ }^{+}$, A. Van den Eeckhout*, J. Dequeker ${ }^{+}$, M. Demedts*
}

Systemic lupus erythematosus, eosinophilia and Löffler's endocarditis. An unusual association. M.Thomeer, Ph. Moerman, R. Westhovens, A. Van den Eeckhout, J. Dequeker, M. Demedts. (C) ERS Journals Ltd 1999.

ABSTRACT: A 24-yr-old male, known since the age of 11 to have a nonerosive arthritis and later diagnosed as having systemic lupus erythematosus (SLE), developed subacute heart failure with diffuse lung infiltrates and died suddenly after having presented a moderate hypereosinophilia for 6 months for which no other causes besides the SLE were found. A post mortem examination revealed Löffler's endocarditis (endocarditis parietalis fibroplastica) with acute pulmonary capillaritis. This represents Löffler's endocarditis in the setting of SLE. To the best of the authors' knowledge, this association has not been reported before. Eur Respir J 1999; 13: 930-933.

\begin{abstract}
*Division of Pulmonary Diseases, **Dept of Pathology and ${ }^{+}$Division of Rheumatology, University Hospital Gasthuisberg, Katholieke Universiteity Leuven, Belgium.
\end{abstract}

Correspondence: M. Demedts, UZ Gasthuisberg, Herestraat 49, B-3000 Leuven, Belgium, Fax: 3216346803

Keywords: Acute pulmonary capillaritis eosinophilia

interstitial lung disease

Löffler's endocarditis

systemic lupus erythematosus

Received: July 271998

Accepted after revision September 221998
Löffler's endocarditis [1] is characterized by an eosinophilic endomyocardial fibrosis and may occur in association with eosinophilia such as hypereosinophilic syndrome (HES), eosinophilic leukaemia, carcinoma, lymphoma, drug reactions, or parasites [2, 3]. Associations with the combination of pulmonary infiltrates and peripheral eosinophilia can be classified into two groups [4, 5]: 1) illnesses in which peripheral eosinophilia is a major component, either of known aetiology such as allergic bronchopulmonary aspergillosis, drug reactions (e.g. to nitrofurantoin, minocyclin or many others), and certain parasitic infections or may be of unknown aetiology such as chronic eosinophilic pneumonia, hypereosinophilic syndrome, and Churg-Strauss syndrome; 2) illnesses in which peripheral eosinophilia occurs infrequently and is a minor component, such as infections (e.g. tuberculosis, brucellosis, histoplasmosis, etc.), neoplasms (e.g. Hodgkin's disease) and immunological disorders (e.g. rheumatoid lung disease, sarcoidosis, etc.).

This report describes a young patient with nonerosive arthritis, later diagnosed as systemic lupus erythematosus (SLE). As the corticosteroid dose was tapered, a moderate eosinophilia became apparent. Within 6 months, diffuse interstitial lung disease and heart failure developed, and the patient died suddenly. At autopsy, typical Löffler's endocarditis and an acute pulmonary capillaritis were found. Such an association makes a report on this case worthwhile because the association of SLE, eosinophilia and Löffler's endocarditis has not hitherto been described.

\section{Case report}

A 24-yr-old-Caucasian male working as an informatician and who was a smoker of 10 cigarettes daily was transferred to the authors' hospital with hypoxia and heart failure. He died suddenly within 2 days of admission.

Since the age of 11, he had suffered from polyarthritis. At the age of 15, human leukocyte antigen (HLA)-B27 and rheumatoid factor were found to be positive, and sulphasalazine was prescribed. At the age of 17, pleuritis and pericarditis, alopecia, skin lesions, photosensitivity, anaemia, lymphopenia a positive antinuclear antibody (ANA), a positive anti-deoxyribonucleic antibody, and a positive leukocyte elastase (LE) test were found. The patient was treated with methylprednisolone $\left(40 \mathrm{mg} \cdot \mathrm{day}^{-1}\right)$, chloroquine $\left(100 \mathrm{mg} \cdot \mathrm{day}^{-1}\right)$, and piroxicam $\left(20 \mathrm{mg} \cdot \mathrm{day}^{-1}\right)$, with good functional results. At the age of 20, methylprednisolone was reduced to $4 \mathrm{mg} \cdot \mathrm{day}^{-1}$. Periungual vascular lesions appeared temporarily, eosinophilia rose to 400 . $\mathrm{mm}^{-3}$ and the rheumatoid factor (RA-latex) was negative. At the age of 22 , he had complaints of polyarthritis and precordial discomfort. Eosinophilia reached $570 \cdot \mathrm{mm}^{-3}$, and circulating immune complexes were positive as well as the extractable nuclear antigen (ENA) (two positive bands, but negative for Sjögren syndrome A (SSA)/Ro, Sjögren syndrome B (SSB)/La, Serratia marcescens, ribonucleoprotein, and Jo1 antibodies). Urinalysis revealed the presence of microscopic haematuria (8-10 red blood cells per field).

At the age of 23 both the complaints and the periungual vasculitis worsened; the eosinophilia ranged 380-1250. $\mathrm{mm}^{-3}$. The urinalysis was normal with normal serum creatinine and urea. One year later, subacute diffuse interstitial lung infiltrates appeared with dry cough, haemoptysis and retrosternal discomfort but no fever. This led to a rapidly progressive respiratory failure (fig. 1). Five days before admission to the authors' hospital, echocardiography revealed a minor pericardial effusion and a thickened heart 


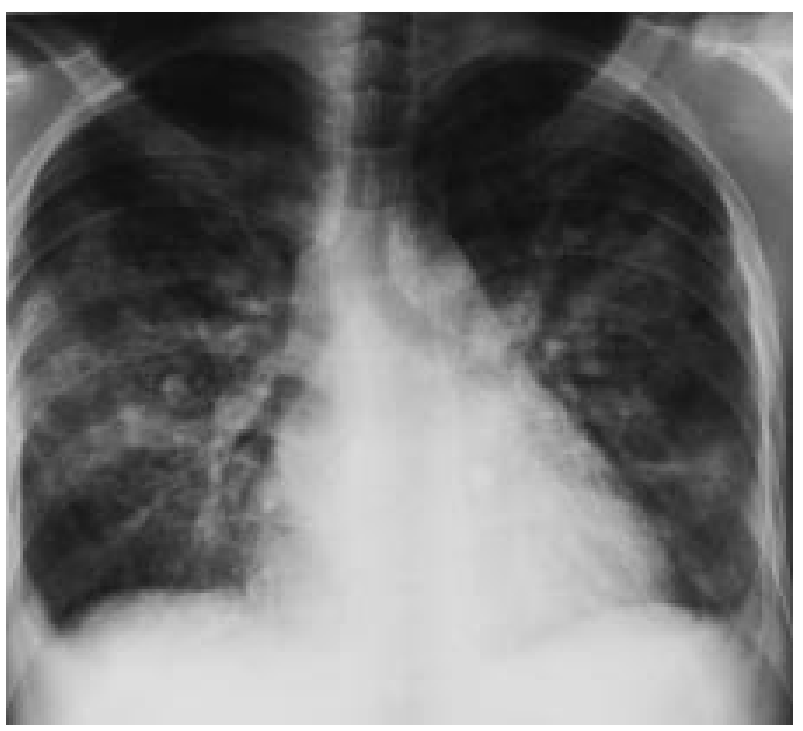

Fig. 1. - Chest radiograph showing patchy reticulo-micronodular infiltrates, increased heart size and obliteration of both costodiaphragmatic angles (note the electrode patch laterally of the right hilum).

muscle. No ventricular thrombi were seen. Microbiological examinations of blood, sputum and urine were negative. The patient was empirically treated with lowmolecular-weight heparin, antibiotics and $40 \mathrm{mg}$ methylprednisolone. The arterial oxygen tension $\left(\mathrm{Pa}_{\mathrm{a}} \mathrm{O}_{2}\right)$ was initially $8.4 \mathrm{kPa}(63 \mathrm{mmHg})$ (room air), but dropped to 7.8 $\mathrm{kPa}(59 \mathrm{mmHg})$ on $2 \mathrm{~L} \mathrm{O} \cdot \mathrm{min}^{-1}$ and to $9.6 \mathrm{kPa}(72$ $\mathrm{mmHg}$ ) on $4 \mathrm{~L} \mathrm{O}_{2} \cdot \mathrm{min}^{-1}$. The patient was referred to the authors' hospital.

On admission (day 1), he was pale, bilateral basal lung crackles were heard, the heart was hyperdynamic with a regular rhythm of 120 beats $\cdot \mathrm{min}^{-1}$, the blood pressure was $100 / 60 \mathrm{mmHg}$, the central venous pressure was clinically increasing and there was a positive hepatojugular reflux. A moderate anaemia was present, liver tests revealed some degree of disturbance (table 1). Serological investigation

Table 1. - Results of the laboratory investigation before admission (-3, -2, -1 yrs; day -3$)$, and on admission (day 1 and 2)

\begin{tabular}{lcccccc}
\hline & -3 yrs & -2 yrs & -1 yr & Day -3 & Day 1 & Day 2 \\
\hline $\begin{array}{l}\text { Haemoglobin } \\
\text { mg.dL }{ }^{-1}\end{array}$ & 14.0 & 14.7 & 12.6 & 11.4 & 10.0 & 0 \\
Haematocrit & 0.43 & 0.43 & 0.37 & 0.33 & 0.30 & - \\
Thrombocytes & 267 & 237 & 229 & 143 & 208 & - \\
$\quad 10^{9} \cdot L^{-1}$ & & & & & & \\
Leukocytes & 5.6 & 7.8 & 5.0 & 8.4 & 7.4 & - \\
$\quad 10^{9} \cdot L^{-1}$ & & & & & & \\
Neutrophils \% & 75 & 82 & 48 & 76 & 92 & - \\
Eosinophils \% & 7 & 7 & 24 & 11 & 1 & - \\
Lymphocytes \% & 11 & 7 & 24 & 7 & 4 & - \\
GOT U.L ${ }^{-1}$ & 6 & 14 & 13 & - & 204 & 227 \\
GPT U.L $L^{-1}$ & 5 & 1 & 6 & - & 349 & 546 \\
$\gamma$ GT U.L & 10 & 12 & 11 & - & 39 & 39 \\
AP U.L $L^{-1}$ & 94 & 133 & 121 & - & 130 & 148 \\
PTT \% & - & - & - & - & 52.7 & - \\
\hline
\end{tabular}

GOT: glutamate oxaloacetate transaminase; GPT: glutamatepyruvate transaminase; $\gamma \mathrm{GT}: \gamma$-glutamyl transpeptidase; AP: alkaline phosphatase; PTT: partial thromboplastin time. showed a positive ANA (homogenous staining pattern) and ENA, negative c- and p- anti-neutrophil cytoplasm antibody (ANCA), a negative RA-latex, the presence of circulating immune complexes, a low 50\% haemolysing dose of complement $(\mathrm{CH} 50)$ of $230 \mathrm{U} \cdot \mathrm{mL}^{-1}$ and severe $\mathrm{T}_{4}$-lymphopenia $\left(79.2 \cdot \mathrm{mm}^{-3}\right)$. Renal function was normal. Lung function showed a severe restrictive defect with a low carbon monoxide diffusing capacity $(29 \%$ predicted). The $\mathrm{Pa}, \mathrm{O}_{2}$ had improved to $13.3 \mathrm{kPa}(100 \mathrm{mmHg})$ on $2 \mathrm{~L} \mathrm{O}_{2} \cdot \mathrm{min}^{-1}$.

When the medical history of this patient was revised with a nonerosive arthritis, pericarditis, a leucopenia of $<4,000 \cdot \mathrm{mm}^{-3}$ on more than two occasions and a lymphopenia of $<1,500 \cdot \mathrm{mm}^{-3}$ on more than two occasions, a positive LE test in December 1988, a positive anti-DNA antibody and an abnormal titre of ANA, the diagnosis of SLE was made based on the American Rheumatism Association classification [6]. Corticosteroids (methylprednisolone $40 \mathrm{mg}$ i.v.) were continued and diuretics (furosemide $2 \times 40 \mathrm{mg}$ i.v.) were added. On day 2 the patient's condition was improved, $\mathrm{Pa}, \mathrm{O}_{2}$ was $10.6 \mathrm{kPa}(80 \mathrm{mmHg})$ on room air, and he even managed a visit to the hospital cafeteria with his family. The next morning (day 3 ) he explained to the nurse that he was feeling well. Fifteen minutes later, he was found dead in bed.

An autopsy was performed: an examination of the heart revealed Löffler's endocarditis with a massive mural thrombosis of the left ventricle (fig. 2) and diffuse fibrous pericardial adhesions. The lung showed an acute pulmonary capillaritis (fig. 3) with a polynuclear infiltrate and multiple pleural adhesions. There were no signs of arylymphoplasmocytic pneumonia, fibrosis or emboli. A centrilobular congestion of the liver was also found. Examination of the major abdominal vessels revealed no thrombi. No parasites were found at the autopsy.

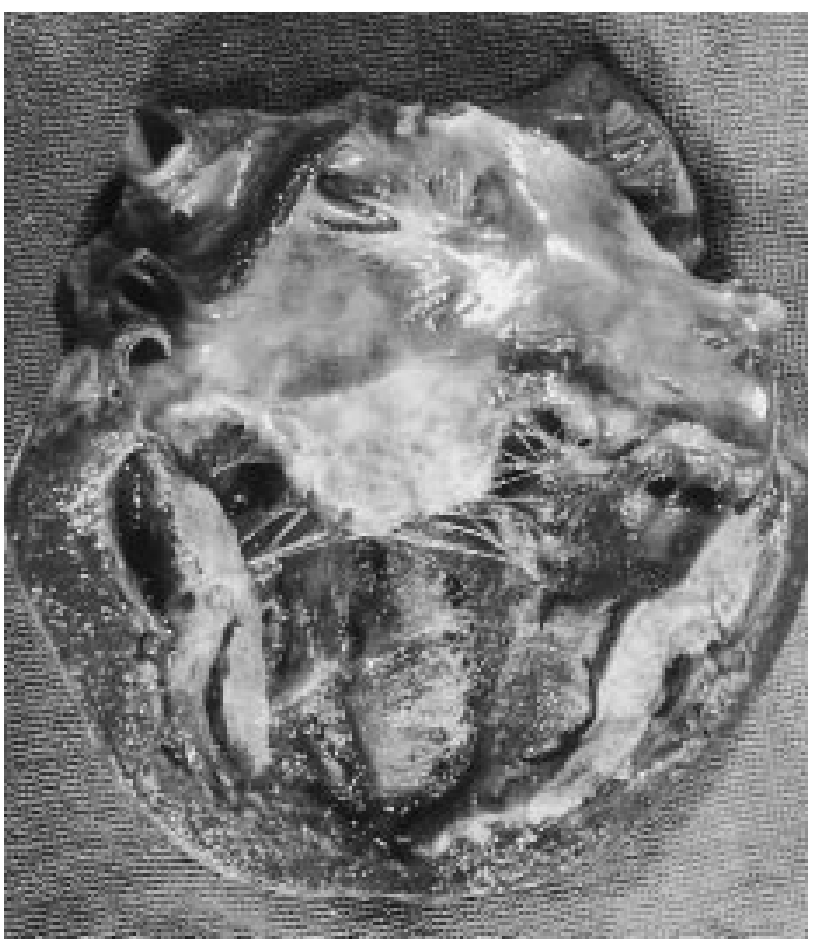

Fig. 2. - Opened left cardiac ventricle, showing massive mural thrombosis. 

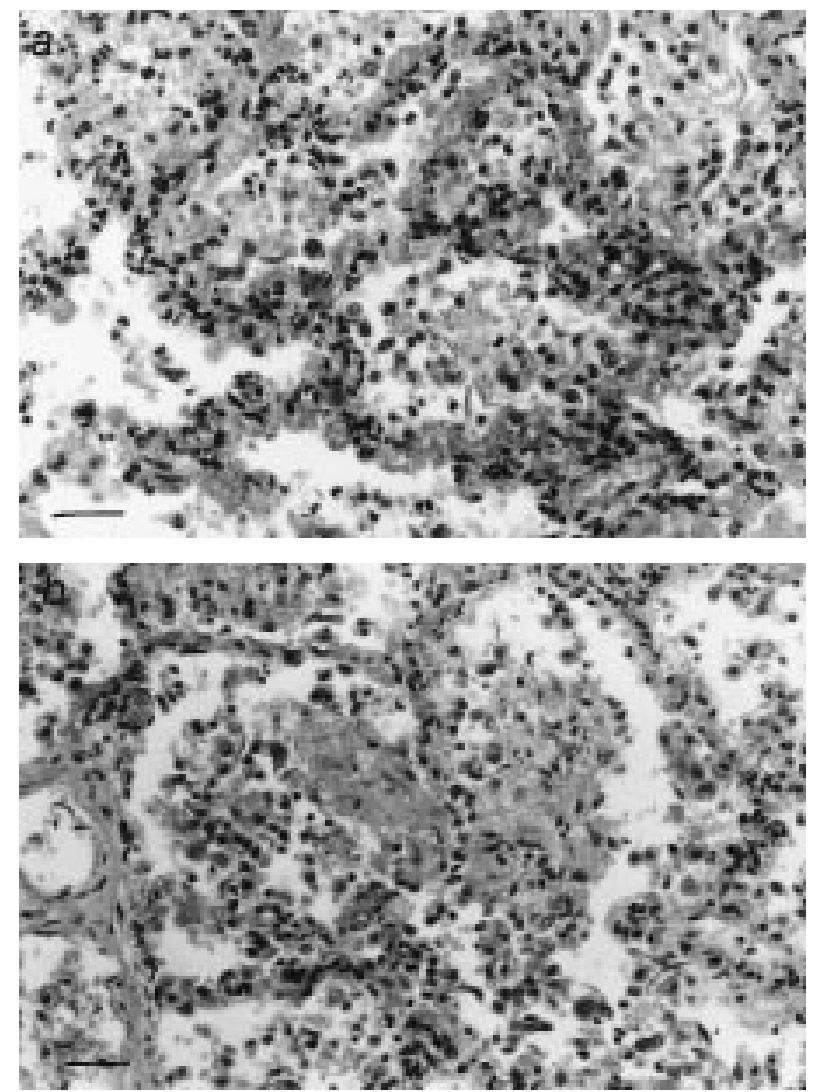

Fig. 3. - Acute pulmonary capillaritis. a) Expansion of the alveolar septa by neutrophils (haematoxylin-eosin stain, internal scale bar $=160$ $\mu \mathrm{m})$. b) Necrosis and rupture of the alveolar septum. The two adjacent alveolar lumens contain a proteinaceous exudate with erythrocytes and necrotic neutrophils (haematoxylin-eosin stain, internal scale bar=125 $\mu \mathrm{m})$.

\section{Discussion}

The 24-yr-old patient, known since the age of 11 with HLA-B27 positive nonerosive arthritis, was transferred to the authors' hospital owing to rapidly worsening dyspnoea with hypoxia. On the basis of his medical history, the diagnosis of SLE was made. He died suddenly while being treated with diuretics, broad-spectrum antibiotics and moderately high doses of corticosteroids. Autopsy revealed acute pulmonary capillaritis combined with Löffler's endocarditis.

Heart involvement is a classic sign in SLE, and inflammation of the heart is often found at autopsy in patients with active SLE [7]. In a prospective study of 70 SLE patients, $57 \%$ were found to have echocardiographic disturbances [8]. In the same study, $20 \%$ of the 70 patients presented with myocardial abnormalities: seven with left ventricle enlargement and nine with left ventricle hypertrophy, but myocarditis was only found in one (clinical features of myocardial dysfunction with a suggestive echocardiographic pattern). In that study, typical signs of Löffler's endocarditis were not described.

This eosinophil-mediated heart damage of Löffler's endocarditis can evolve through three stages: a necrotic, a thrombotic and a late fibrotic stage [3,9]. Echocardiography does not detect abnormalities in the first stage. In the second stage, mural thrombi are seen in one or both ventricles along the damaged endocardium [3], and an increased left ventricular wall thickness and an abnormal motion of the posterior valve leaflet are revealed $[2,10]$. Finally the fibrotic stage with fibrous thickening of the myocardium manifests itself as a restrictive cardiomyopathy [10]. In the current patient, on autopsy a thickened and fibrotic endocardium was found with an intracavitary thrombus in the left ventricle (fig. 2). The combination of endocardial fibrosis with an intracavitary thrombosis causes a restriction to inflow with outflow obliteration. These findings are typical for Löffler's endocarditis [3, 11, 12].

Cardiac involvement or Löffler's endocarditis is frequently seen in the hypereosinophilic syndrome [3], an idiopathic syndrome characterized by: 1) a persistent elevation in the total eosinophilic count $\left(>1,500 \cdot \mathrm{mm}^{-3}\right)$ for over 6 months or death within 6 months; 2) associated multiorgan damage; and 3) no detectable underlying causes for the eosinophilia [13]. The current patient did not meet criteria (1) or (3). The cardiac disease in the patient was speculated to be not directly due to SLE, but was secondary to the increase of eosinophils after the corticosteroids were tapered off. Indeed, eosinophils have been shown to be able to cause myocardial toxicity especially due to their cationic proteins $[11,14]$. According to ROBERTs et al. [15], it is likely that Löffler's endocarditis, associated with other diseases, is due to the eosinophilia itself and not to an unrecognized underlying factor. In this respect Löffler's endocarditis has been reported in patients with variegated eosinophilic responses, whether they were secondary to drugs or to parasitic diseases $[3,15]$.

Animal models of hypereosinophilia caused by parasitic infection have demonstrated a cardiac dysfunction and accumulation of eosinophils in the myocardium, in addition to histological alterations leading to decreased myocardial compliance [16]. In the current patient, neither serological nor stool examination tests were carried out to exclude the presence of parasites because no clinical signs of parasitic infection were present; also, on autopsy, no parasitic infestation was found. In SLE, as in rheumatoid arthritis, marked eosinophilia has occasionally been described [17, 18]. However, to the best of the authors' knowledge, no Löffler's endocarditis has been reported in this context.

At autopsy, the patient's lung showed acute pulmonary capillaritis, with polymorphonuclear cell infiltration and multiple pleural adhesions. A variety of pulmonary parenchymal lesions have been described in SLE, ranging from acute lupus pneumonitis syndrome to a more chronic diffuse interstitial disease with subacute or recurrent infiltrates [19]. A microscopic examination of the patient's lung revealed expansion of the interalveolar septa by polymorphonuclear cells, which caused capillary thromboses with necrosis and rupture of the alveolar septa (fig. 3). The alveolar lumens were filled with a fibrinous exudate. These lesions are typical for pulmonary capillaritis [20,21]. This entity is not pathognomonic for SLE, and has been reported in Wegener's granulomatosis, microscopic polyarteritis, Goodpasture's syndrome, idiopathic pulmonary renal syndrome, Behçet syndrome, Henoch-Schönlein purpura, IgA nephropathy, antiphospholipid syndrome, progressive systemic sclerosis and phenytoin use [20]. In hypereosinophilia the presence of pulmonary capillaritis has not been described [20]. In the current case, the autopsy also demonstrated the presence of fibrotic pleural lesions. Pleural disease, i.e. adhesions, thickening or effusion, may be found 
at autopsy in up to $93 \%$ of the cases affected by SLE; however, clinically apparent disease is less frequent [19].

In conclusion, the patient, with an unrecognized systemic lupus erythematosus, died suddenly from a restrictive cardiomyopathy with intracavitary thrombosis and associated acute pulmonary capillaritis. These cardiac lesions were probably related the blood eosinophilia, and the latter was considered secondary or associated to systemic lupus erythematosus, as no other cause was detected.

\section{References}

1. Löffler W. Endocarditis parietalis fibroplastica mit Bluteosinophilie: ein eigenartiges Krankheitsbild. Schweiz Med Wochenschr 1936; 17: 817.

2. Felice PV, Sawicki J, Anto J. Endomyocardial disease and eosinophilia. Angiology 1993; 7: 869-874.

3. Weller PF, Bubley GJ. The idiopathic hypereosinophilic syndrome. Blood 1994; 83: 2759-2779.

4. Winchester RJ, Litwin SD, Koffler D, Kunkel HG. Observations on the eosinophilia of certain patients with rheumatoid arthritis. Arthritis Rheum 1971; 14: 650-665.

5. Schatz M, Wasserman S, Patterson R. The eosinophil and the lung. Ann Intern Med 1982; 142: 1515-1519.

6. Tan EM, Cohen AS, Fries JF, et al. The 1982 revised criteria for the classification of systemic lupus erythematosus. Arthritis Rheum 1982; 25: 1271-1277.

7. Mills JA. Medical progress: systemic lupus erythematosus. $N$ Engl J Med 1994; 330: 5-6.

8. Cervera R, Font J, Paré P, et al. Cardiac disease in systemic lupus erythematosus: a prospective study of 70 patients. Ann Rheum Dis 1992; 51: 156-159.

9. Brockington IF, Olsen EG. Löffler's endocarditis and Davies' endomyocardial fibrosis. Am Heart J1973; 85: 308.
10. Kushwaha SS, Fallon JT, Fuster V. Restrictive cardiomyopathy. $N$ Engl J Med 1997; 336: 267-276.

11. Liesveld JL, Abboud CN. State of the art: the hypereosinophilic syndrome. Blood Rev 1991; 5: 29-37.

12. Adler CP. Obstruktiv-restriktive Kardiomyopathie: zur Klinik und Pathologie der Löfflerschen Endokarditis. Versicherungsmedizin 1989; 41: 151-154.

13. Chusid MJ, Dale DC, West BC, Wolff SM. The hypereosinophilic syndrome: analyses of 14 cases with review of the literature. Medicine 1975; 54: 1-27.

14. Tai PC, Ackerman SJ, Spry CJ, Dunnette S, Olsen EG, Gleich GJ. Deposits of eosinophil granule proteins in cardiac tissues of patients with eosinophilic endomyocardial disease. Lancet 1987; 1: 643-647.

15. Roberts WC, Liegler DG, Carbone PP. Endomyocardial disease and eosinophilia. Am J Med 1969; 46: 28-42.

16. Schaffer SW, Dimayuga ER, Kayes SG. Development and characterization of a model of eosinophil-mediated cardiomyopathy in rats infected with Toxocara canis. $\mathrm{Am}$ $J$ Physiol 1992; 262: H1428-H1434.

17. Panush R, Franco A, Schur P. Rheumatoid arthritis associated with eosinophilia. Ann Intern Med 1971; 75: 199205.

18. Clauw DJ, Crofford LJ. Eosinophilic rheumatic disorders. Rheum Dis Clin North Am 1995; 21: 231-246.

19. King TE. Connective tissue disease. In: Schwarz MI, King TE, eds. Interstitial Lung Disease. St. Louis, Mosby Year Book, 1993; pp. 271-308.

20. Green RJ, Ruoss S, Kraft SA, Berry GJ, Raffin TA. Pulmonary capillaritis and alveolar haemorrhage. Chest 1996; 110: 1305-1316.

21. Haupt HM, Moore GW, Hutchins GM. The lung in systemic lupus erythematosus: analysis of the pathologic changes in 120 patients. Am J Med 1981; 71: 791-798. 